\title{
Modification of polyvinylchloride by the silicates on the base of rice husk
}

\author{
Elena Gotlib ${ }^{1}$, Dilyara Sadykova ${ }^{1}$, Ekaterina Yamaleeva $^{2}$, and Alla Sokolova $^{3}$ \\ ${ }^{1}$ Kazan National Research Technological University, Department of technology of synthetic rubber, \\ 420015, Karl Marx street 68, Kazan, Russia \\ ${ }^{2}$ Kazan National Research Technological University, Department of technological equipment of \\ medical and light industry, 420015, Karl Marx street 68, Kazan, Russia \\ ${ }^{3}$ Moscow State University of Civil Engineering, Yaroslavskoe shosse, 26, Moscow, 129337, Russia
}

\begin{abstract}
As a modifying additive in PVC-compositions, silicates produced by means of rice husk processing are of practical interest. Rice husk ash obtained by burning at $350^{\circ} \mathrm{C}$, along with synthetic and naturally occurring wollastonite, significantly reduce plasticizer's migration from the PVC-composition due to their porosity. This is due to the fact that the part of hydroxyl components of the plasticizer EDOS has adsorbed on the surface or retained by the silicates pores. Along with that, Miwoll 10-97 ensures a greater decrease in plasticizer's migration than synthetic calcium silicate on the base of rice husk ash. When all the researched silicates are modified by the rice husk and naturally occurring wollastonite, heat stability of PVC-compositions grows. This is preconditioned by the alkaline origin of the surface of filling compounds that allows their possible reaction with chlorine hydride released from PVC during thermal decomposition. Synthetic and naturally occurring wollastonite enhance strain-strength properties of PVC-compositions whereas silicates on the case of rice husk reduce these parameters.
\end{abstract}

\section{Introduction}

Polyvinylchloride is one of the most wide spread large-tonnage synthetic polymers applied in the various spheres of national economy [1]. Relatively low temperatures of the start of individual PVC-decomposition and the mechanism of its thermal breakdown determine the necessity of application of plasticizers and modifiers or fillers in the composition of materials. The former lower the temperature of processing and increase elasticity, whereas the latter perform as heat stabilizers and anti-oxidizing agents [2].

Silicates obtained by rice husk $(\mathrm{RH})$ processing are of particular interest when used as modifiers for PVC-compositions [3-5]. RHA mainly consists of amorphous silica ( $\mathrm{SiO} 2$ ) and other metallic impurities. Rice husk represents protective coating of rice grains that are dehusked and separated in the milling process. This is an abundantly available by-product of the rice-processing industry and contains about $30 \div 50 \%$ of organic carbon. Throughout a typical process of milling, the husks are being removed from the raw grain to reveal whole brown rice. Upon further milling, the bran layer is removed to yield white rice. Current rice production in the world is estimated to be 700 million tons, therefore utilizing this largetonnage waste product is of acute importance. Rice husk constitutes about $20 \%$ of the weight of rice and its composition is as follows: cellulose $(50 \%)$, lignin $(25 \%-30 \%)$, silica $(15 \%-20 \%)$, and moisture $(10 \%-15 \%)$. Bulk density of rice husk is low and lies in the range $90-150 \mathrm{~kg} / \mathrm{m}^{3}$. 
It has attracted an increasing interest as a renewable source material. Engineered silica particles have been thoroughly investigated as possible biological applications, bioremediation, and energy storage as well as building materials. By means of increasing application of engineered silica particles, the synthesis of silicates from renewable resources is considered sustainable. The application of rice husk silica for the purpose of synthesis of engineered silica particles has certain advantages not only for the national economy but also in mitigating environmental problems. The most commonly used method for production of silica from rice husks is direct combustion that leads to obtaining rice husk ash containing $85-95 \%$ of pure silica.

Thus, in the paper [6] it was proven that naturally occurring wollastonite (calcium silicate) lowers PVC-migration from the compositions and enhances their heat stability due to alkaline nature of its surface [7].

\section{Materials and methods}

For manufacturing of the materials, there have been used the following: emulsion PVC of the grade 372NF (TR (Technical Requirements) 2212-002-83385954-2012), plasticizer EDOS (TR 2493-003-13004749-93), and micro marble of the grade RM-130 (TR 5716001-99242323-2007). The plasticizer EDOS comprises a mixture of derivatives of 1,3dioxane and alcohols and their high-boiling ethers, the main component of which is 1,7-bis(4-methyl-1,3-dioxan-4-yl)-3,5-dioxaheptane. Product EDOS has a relatively low cost compared with phthalate plasticizers and can be used to produce non-critical plasticized PVC materials and articles.

As modifiers, there have been used rice husk as (RHA) obtained at the temperatures $350^{\circ} \mathrm{C}\left(\mathrm{RHA}_{1}\right)$ and $800^{\circ} \mathrm{C}\left(\mathrm{RHA}_{2}\right)$, respectively; synthetic wollastonite obtained on the base of $\mathrm{RHA}_{2}$ and calcium oxide from the limestone, when the ratio $\mathrm{CaO}: \mathrm{SiO}_{2}$ is equal to $1.2: 11$ and temperature $900^{\circ} \mathrm{C}$ during 3 hours [8]. For comparison, naturally occurring wollastonite of the grade Miwoll 10-97 (TR 577-006-40705684-2003) was investigated. Miwoll 10-97 gives to the materials special resistance to UV radiation and water resistance, has a biocidal effect, does not contain asbestos-forming substances, is not carcinogenic and is classified as safe, provides a pronounced reinforcing effect in compositions operated under conditions of deformation, alternating, abrasive loads. The principal areas of its application include paints, varnishes and critical building materials, plastics, rubber and friction products, porcelain and faience ceramics, metallurgical and electrode production.

Plasticizer's migration from PVC-compositions has been determined by the samples' weight change in compliance with the European Standard EN 664:1994.

Infrared spectra of polyvinylchloride films have been taken by the IF-Fourier spectrometer Frontier (Perkin Elmer) with the auxiliary device Universal ATR Sampling (Frustrated Total Internal Reflection (FTIR)), by means of applying the researched sample directly on the FTIR-crystal. The scanning range was in the area of 4000-600 $\mathrm{cm}^{-1}$.

Heat stability of PVC-compositions has been evaluated according to the All-Union Standard GOST 14041-91 "Plastics. Determination of the tendency of compounds and products based on vinyl chloride homopolymers and copolymers to evolve hydrogen chloride and any other acidic products at elevated temperatures. Congo red method".

$\mathrm{PH}$ of aqueous slurries of the fillers' samples have been measured by the combined gauger

Seven Multi under the GOST 21119.3-91 "General methods of test for pigments and extenders. Determination of $\mathrm{pH}$ value of an aqueous suspension". Measurement range: $2.000 \div 20.000 \mathrm{pH}$ Resolution: $0.001 / 0.01 / 0.1$ Limits of error: \pm 0.002 . Measuring temperature: $30.0^{\circ} \mathrm{C} \div 130.0^{\circ} \mathrm{C}$ Resolution: $0.1{ }^{\circ} \mathrm{C}$. Limits of error: $\pm 0.1{ }^{\circ} \mathrm{C}$. Automatic (ATC) or manual (MTC) temperature compensation. Ambient conditions: Room temperature: $5^{\circ} \mathrm{C} \div 40^{\circ} \mathrm{C}$. Relative humidity: $80 \%$ at $31^{\circ} \mathrm{C}$, decreasing linearly to $50 \%$ at $40^{\circ} \mathrm{C}$. 
Pore volume and pore-size distribution are crucial parameters for porous materials. Voids volume has been determined under the BJH method on the analyzer of the surface area and the voids size "Nova 1200e" ISO 15901-2. The BJH (Barrett-Joyner-Halenda) method is considered the most widely applied method for pore-size determination.

Tensile strength and the coefficient of strain have been estimated under the GOST 11262-80 "Plastics. Tensile test method".

\section{Results and discussions}

The analysis of the experimental results gives an evidence that rice husk ash obtained by burning at $350^{\circ} \mathrm{C}$, due to its high porosity (table 1), lowers migration of a plasticizer from the PVC-composition at a greater extent. The results of the modifier's impact on the properties of the silicates are presented in the table 1 .

The similar effect is observed in the case of application of synthetic and naturally occurring wollastonite (table 2). In addition, Miwoll 10-97 ensures the more prominent lowering of plasticizer's migration than synthetic calcium silicate on the base of rice husk ash.

Table 1. PH of the silicates surface and their porosity.

\begin{tabular}{|c|c|c|c|c|}
\hline $\mathbf{N}$ & $\begin{array}{c}\text { Type of a } \\
\text { modifier }\end{array}$ & $\begin{array}{c}\text { PH of the } \\
\text { surface }\end{array}$ & $\begin{array}{c}\text { Voids' volume under } \\
\text { the Halsey method, } \\
\mathbf{c m}^{\mathbf{3}} / \mathbf{g}\end{array}$ & $\begin{array}{c}\text { Average void } \\
\text { diameter under BJH, } \\
\mathbf{n m}\end{array}$ \\
\hline 1 & $\mathrm{RHA}_{1}$ & 10.31 & 0.003 & 3.387 \\
\hline 2 & RHA $_{2}$ & 8.92 & 0,001 & 3.308 \\
\hline 3 & $\begin{array}{c}\text { Synthetic } \\
\text { wollastonite }\end{array}$ & 11.8 & 0.011 & 3.674 \\
\hline 4 & Miwoll 10-97 & 9.7 & 0.018 & 3.492 \\
\hline
\end{tabular}

This could be preconditioned by the fact that naturally occurring wollastonite has a greater volume of voids of a larger diameter [8] as well as the total voids volume despite of the slightly smaller average size of the voids (see table 1). The lowering of plasticizer's migration from PVC-compositions could be explained by the fact that the part of its easily volatile components was absorbed on the silicates surface or penetrated into their structural voids.

It could be assumed by the authors that formation of hydrogen bonds between hydroxyl components of the plasticizer EDOS (dioxane and other spirits [9]) and wollastonite takes place according to the scheme presented below (figure 1): 


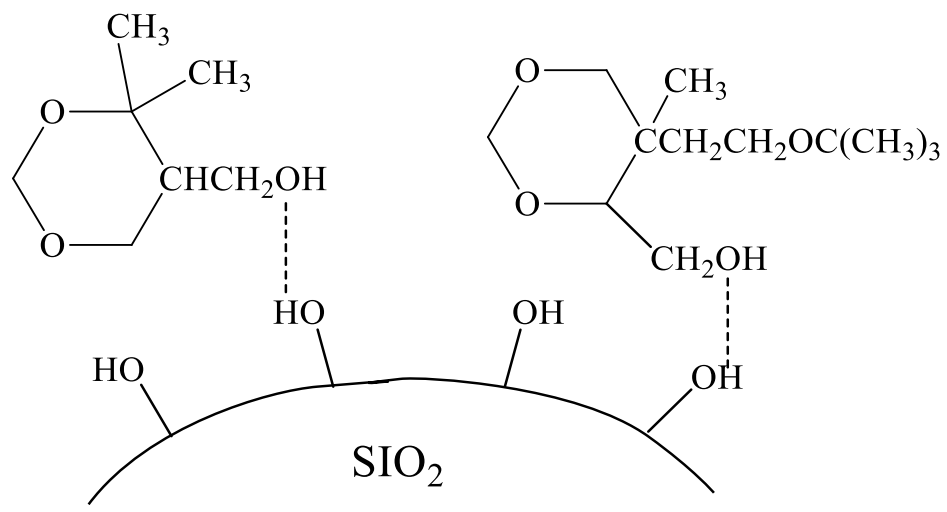

Fig. 1. The diagram depicting hydrogen-bond formation between hydroxyl components of the EDOS plasticizer

In order to validate this assumption, the following experimental test has been carried out. The equal amount of the plasticizer EDOS has been placed in two retorts of the same size and shape, then wollastonite, in the quantity of $10 \%$ of the plasticizer's mass, was added into the first retort while mixing. Both retorts were then heated up to the temperature of $130^{\circ} \mathrm{C}$. Having cooled the retorts down, infrared spectra of the samples were taken (figure 1). Along with that, in the case of wollastonite application, it had been preliminary removed by means of centrifugal process.

Fixed lowering of peak intensity in the range of $3700-3200 \mathrm{~cm}^{-1}$ for the samples undergone thermal treatment gives a plausible evidence about the reduction of hydroxyl groups' concentration. This also confirms evaporation of hydroxyl components of the plasticizer during the heating process.

Almost equal weight loss (about 20\%) for both researched samples, which undergone thermal treatment, and less significant peak intensity in the range $3700-3200 \mathrm{~cm}^{-1}$ for the sample containing wollastonite (figure1). This finding confirms the assumption that the part of hydroxyl components of the plasticizer EDOS was absorbed by the wollastonite surface or retained in its voids. 


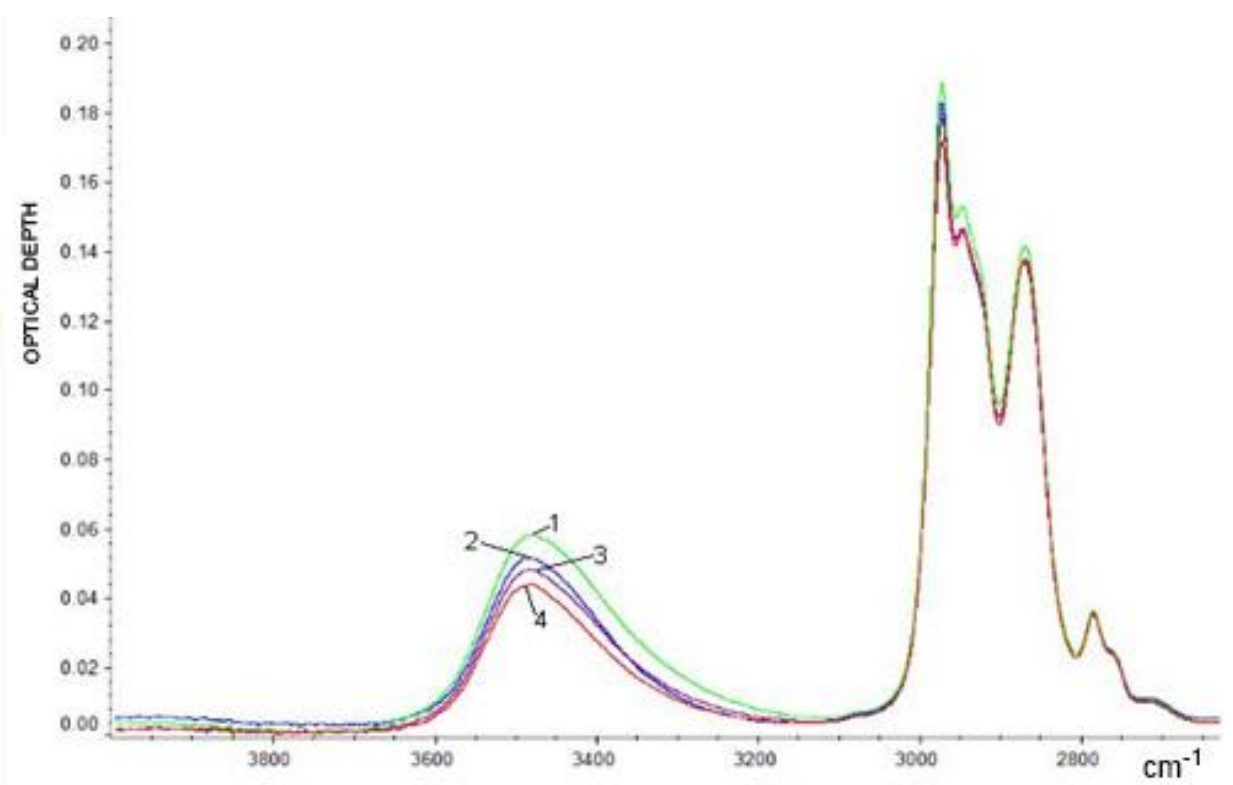

Fig. 2. Infrared spectra in the range of hydroxyl groups of the initial plasticizer EDOS (1), after the plasticizer's heating (2), of the mixture EDOS-wollastonite before (3) and after heating (4).

At the same time, rice husk ash obtained at the temperature of $800^{\circ} \mathrm{C}$, quite the opposite, increases the plasticizer's migration (the results are presented in the table 2). This could be related to the insignificant voids volume of this silicate (table 1).

In addition, in the composition of $\mathrm{RHA}_{2}$ there is crystalline silica dioxide - cristobalite [10], which is less reactive, than amorphous silica included in the composition of RHA . Cristobalite is a mineral polymorph of silica formed at very high-temperatures. It has the same chemical formula as quartz, $\mathrm{SiO}_{2}$, but is distinguished by its crystal structure. The more open structure of cristobalite in comparison to quartz allows a certain degree of incorporation of other elements into the crystal structure.

Heat stability of polyvinylchloride compositions augments when all the researched silicates on the base of rice husk are applied as modifying agents (the results are presented in the table 2). The same applies to naturally occurring wollastonite. This phenomenon could be explained by high thermal stability of silica dioxide and calcium silicates [11].

Heat stability growth could also be attributed to the ability of silicates to accept free radicals that are formed during the process of thermal oxidative breakdown of a polymer.

Table 2. The properties of PVC-compositions modified by the silicates on the base of rice husk ash and Miwoll 10-97 for comparison purposes.

\begin{tabular}{|c|c|c|c|c|}
\hline Type of a modifier & $\begin{array}{c}\text { Heat stability, } \\
\text { minutes }\end{array}$ & $\begin{array}{c}\text { Coefficient of } \\
\text { strain, \% }\end{array}$ & $\begin{array}{c}\text { Strength, } \\
\text { MPa }\end{array}$ & $\begin{array}{c}\text { Migration of } \\
\text { plasticizer, \% }\end{array}$ \\
\hline Non-modified & 2.8 & 150 & 3.4 & 7.1 \\
\hline RHA $_{1}$ & 4.8 & 88 & 2.77 & 5.8 \\
\hline RHA $_{2}$ & 4.6 & 78 & 1.82 & 7.8 \\
\hline $\begin{array}{c}\text { Synthetic } \\
\text { wollastonite }\end{array}$ & 3.1 & 158 & 4.1 & 6.4 \\
\hline Miwoll 10-97 & 4.8 & 158 & 3.6 & 5.3 \\
\hline
\end{tabular}

Moreover, as was shown in the paper [12], $\mathrm{pH}$ of the aqueous tincture of the applied mineral fillers has a noticeable impact on the value of heat stability of the modified PVC- 
compositions. This is also related to the rise of heat stability of polyvinylchloride compositions modified by naturally occurring and synthetic wollastonite and rice hush ash, which are characterized by alkaline nature of their surface (the results are given in the table 1). This preconditions the possibility of reaction between these silicates and chlorine hydride emitted by PVC when exposed to elevated temperatures [13]. The latter, in its turn, reduces the decomposition of the plasticizer EDOS due to the fact that chlorine hydride facilitates breakdown of dioxane nucleus of this plasticizer, not stable in acid media [9].

Despite the higher surficial $\mathrm{pH}$ (table 1), synthetic wollastonite enhances heat stability of the epoxy compositions at a lesser degree than rice husk ash and Miwoll 10-97 (the results are presented in the table 2). This could be preconditioned by the larger particle size if compared with natural Miwoll 10-97 [14] that reduces interaction on the phase boundary matrix-solid surface.

Tensile strength of polyvinylchloride compositions and their coefficient of strain grow when modified by naturally occurring and synthetic wollastonite (the results are outlined in the table 2). This is connected with the needle-like shape of wollastonite particles providing micro reinforcing effect. At a lesser extent, this effect is observed in the case of Miwoll 1097 application.

At the same time, rice husk ash lowers the described stress-strain characteristics; moreover, rice hush ask obtained at the higher temperature of burning affects more significantly (table 2). This phenomenon could be ensured by the greater degree of crystallinity of rice hush ash, and consequently, the lower chemical activity of calcium dioxide.

Thus, acid-base characteristics of the silicates surface, as well as porosity of silicates, crystallinity and the particle size affect heat stability of modified polyvinylchloride compositions and migration of a plasticizer from them.

The effect of augmentation of stress-strain properties is observed when PVCcompositions are modified by wollastonite due to the anisodiametric shape of the wollastonite particles.

Thus, it could be concluded that silicates obtained on the base of rice husk ash have an impact on lowering strength and tensile elongation of the materials.

\section{Conclusions}

Experimental data have shown that ash obtained at the temperature of rice husk burning $350^{\circ} \mathrm{C}$, as well as naturally occurring and synthetic wollastonite downgrade the migration of a plasticizer contacting in the polyvinylchloride composition. This is related to porosity of these silicates and absorption of hydroxyl components of the plasticizer EDOS on their surface due to hydrogen bonds formation.

When all the researched silicates on the base of rice husk, as well as naturally occurring wollastonite are applied as modifiers, there observed the growth of heat stability of PVCcompositions. This increase in heat stability is more prominent when Miwoll 10-97 and rice husk ash obtained at the temperature of $350^{\circ} \mathrm{C}$ are used.

Thus, it could be said that synthetic and naturally occurring wollastonite enhances stress-strain properties of polyvinylchloride compositions, while the silicates obtained on the base of rice husk downgrade these parameters.

\section{References}

1. S. Pakhomov, I. Triphonova, V. Burmistrov, Polyvinylchloride compositions, Ivanovo, Russia (2010)

2. M. Kerber, V. Vinogradov, G. Golovkin, Polymer composite materials: structure, properties, technology, Saint-Petersburg, Russia (2008) 
3. U. Kalapathy, A. Proctor, J. Shultz, An improved method for production of silica from rice husk ash, J. Bioresource Technology, 85 (3) (2002)

4. I. Hamisah, R. Shamsudin, M. Azmi, A. Hamid, A. Jalar, Synthesis and Characterization of Nano-Wollastonite from Rice Husk Ash and Limestone, J. Materials Science Forum, 756 (2013)

5. D. Chaudhary, M. Jollands, F. Cser, Utilization of rice husk ash as fillers in polymers: A review, J. Silicon Chemistry. 1 (2002)

6. E. Gotlib, A.Sokolova, R. Kozhevnikov, E. Il'icheva, Application of wollastonite in the PVC-compositions for linoleum manufacturing, J. Bulletin of Kazan Techn. University, 17 (19) (2014)

7. V. Tyulnin, V. Tkach, V. Eirich, Wollastonite, the unique mineral multifunctional raw material, J. Ore and metals (2003)

8. E. Gotlib, Ha Phyuog, G. Islamova, E. Yamaleeva, T. Lygina, Obtaining the fillers of epoxy materials on the base of rusk husk, J. Polymers in construction 1 (7) (2019)

9. A. Dykamn, V. Pinson, A. Flegontov, V. Shefter, Structure of high boiling by-products of isoprene and chemical mechanisms of its formation, J. Oil processing and oil chemistry, 8 (2013)

10. E. Gotlib, M. Ntsumu, R. Shelton, A. Valeeva, E. Yamaleeva, The influence of the temperature of obtaining rice husk ash on its composition and modifying effect, J. Bulletin of Techn. University, 23 (11) (2020)

11. I. Zlotnikov, V. Shapovalov, The influence of high dispersive modified silicates on the thermal process in polymers, J. Proceedings of Gomel State Technical University 32(69) 48 (2017)

12. N. Dimidenko, L.Podzorova, V.Skorokhodov, V.Shevchenko, J. Glass and Ceramics 9 $15(2001)$

13. E. Gotlib and etc. J. Sci. Israel-Technological Advantages 2 (2013)

14. E. Gotlib, E. Yamaleeva, Synthetic wollastonite - the methods of obtaining, properties and application as a filler for epoxy polymers. Kazan, Russia (2020) 